\title{
Orthopedic Surgery and its Relationship to the Opioid Epidemic: A Forum and Consensus
}

\author{
Charles N. Cornell, MD
}

Received: 9 December 2018/Accepted: 16 December 2018/Published online: 30 January 2019

(C) Hospital for Special Surgery 2019

Welcome to this special issue of HSS Journal ${ }^{\circledR}$. This is indeed a "special" issue: it addresses the current opioid crisis and the role that orthopedic institutions may play in shaping its resolution. The journal's editorial board recommended that the journal partner with HSS's Education Institute to hold a forum to address opioid use and misuse in orthopedic surgery, with a particular focus on opioid prescribing following total hip or knee arthroplasty. Seth Waldman, MD, director of the Pain Management Division in HSS's Department of Anesthesiology and a world-recognized expert in the management of pain and opioid pharmacology, agreed to act as the co-chair of the forum.

With Dr. Waldman's guidance, our planning committee identified experts from a variety of disciplines, including orthopedics, anesthesiology, peri-operative care, bioethics, addiction, health information technology, and law, who agreed to participate in this program. On June 1, 2018, we conducted the forum at HSS as a day-long seminar. The participants were charged with delivering a presentation that addressed their expertise as it related to post-surgical pain management and the opioid crisis. These experts also assisted in drafting a consensus statement summarizing the recommendations of all who presented at the day-long meeting.
This issue of HSS Journal presents contributions by the forum members, including our final consensus statement, as well as by clinicians and researchers from around the country who are grappling with the opioid crisis. The articles presented here include reports of original research, reviews, and commentaries on various topics related to opioid prescribing and pain management after arthroplasty.

I personally find these contributions to be exceptional. I believe this forum can serve as a potent example of the true potential of academia to address complex societal crises and to propose realistic solutions that will move our society forward. I feel lucky and honored to have participated in the forum, and I hope all of our readers benefit from its presentation here.

\section{Compliance with Ethical Standards}

Conflict of Interest: Charles N. Cornell, MD, reports receiving personal fees from Exactech, Inc., for speaking engagements, outside the submitted work.

\section{Human/Animal Rights: N/A}

Informed Consent: N/A

Required Author Forms Disclosure forms provided by the author are available with the online version of this article. 